\title{
Exploring Home-use Test to Assess Urban Consumers' Acceptance and Likelihood to Purchase Naturally Fortified Instant Whole Meal Sorghum-maize Flour Blends in Eldoret, Kenya
}

\author{
Violet K. Mugalavai ${ }^{1}$ \\ ${ }^{1}$ School of Agriculture, Department of Family and Consumer Sciences, University of Eldoret, Kenya \\ ${ }^{1}$ Correspondence: Violet K. Mugalavai, School of Agriculture, Department of Family and Consumer Sciences, \\ University of Eldoret, Kenya. E-mail: violet.mugalavai@uoeld.ac.ke
}

Received: April 7, 2020

Accepted: May 1, $2020 \quad$ Online Published: May 11, 2020

doi:10.5539/jfr.v9n3p19

URL: https://doi.org/10.5539/jfr.v9n3p19

\begin{abstract}
Fortification of staple foods has the potential to alleviate micronutrient and protein energy malnutrition in sub Saharan Africa. However, natural food fortification often alters sensory attributes such as flavour, aroma, appearance, texture and other features in ways that may affect target consumer overall acceptance and willingness to purchase. This study examined urban consumers' acceptance and likelihood to purchase wholemeal instant flours that were fortified using plant based sources. A home-use test (HUT) sensory experiment was conducted in Eldoret, Kenya among 154 urban dwellers in the middle and high level income group living in three gated estates. 5 different flour composites using sorghum, maize, baobab, orange fleshed sweet potato (OFSP) and grain amaranth were used to make both thin (uji) and thick (ugali) porridges. The results showed that urban consumers could distinguish stiff porridge (ugali) and thin porridge (uji) made from the 5 flour varieties. They preferred uji, expressed by higher mean general acceptability scores made from all the flour varieties $(\mathrm{M}=4.15-\mathrm{M}=3.83)$ to ugali $(\mathrm{M}=3.50-\mathrm{M}=3.17)$, for appearance, aroma, texture in hand and mouth, significant at $\mathrm{p}<0.05$. Mothers' and childrens' overall acceptance ratings for both sets of products did not differ, showing the ability of mothers to influence a child's overall acceptance of a product. Further, more than $80 \%$ consumers were likely to purchase and use the instant flour. Pearson correlation showed significant positive correlations $(* \mathrm{P}<.05 ; \& * * \mathrm{P}<.01)$, for product fit for all family, with nutritional and health benefits, and product that is introduced by a close friend as the main factors driving their likelihood of purchase. We conclude that HUT is effective for assessing consumer acceptance as far as product sensory characteristics and consumer adoption of a new product, and can be used by industry before market penetration.
\end{abstract}

Keywords: consumer acceptance, wholemeal instant flours, home-use test, sensory evaluation, likelihood of purchase

\section{Introduction}

In the developing world, approximately $32 \%$ of children under 5 years are stunted while $20 \%$ are underweight (Black et al., 2008). Diets consumed by populations in these countries are frequently deficient in macronutrients (protein, carbohydrates and fat, leading to protein-energy malnutrition), micronutrients (electrolytes, minerals and vitamins, leading to specific micronutrient deficiencies) or both, causing further adverse effects on health (Müller \& Michael, 2005). In particular, maize and sorghum-based diets with limited variations typical for rural populations in East and Southern Africa, inadequate intakes of quality protein and, specifically, of essential amino acids (lysine, threonine and arginine) can be a significant public health problem (Proietti, Frazzoli \& Mantovani, 2015). Other dietary sources of these amino acids, in particular legumes and animal source foods, are often not available or are too expensive for nutritionally-vulnerable populations in low-income countries (De Groote et al., 2014).

Micronutrient malnutrition is widely recognized as a public health problem, for instance Vitamin A deficiency accounts for $6 \%$ of all deaths and 5\% of the total disease burden among preschool children (Black et al., 2008). Additionally, iron deficiency anaemia and infections are responsible for a large part of the global morbidity and mortality that occurs in children aged less than 5 years old in sub-Saharan Africa (Jonker et al., 2017). As in much of Sub-Saharan Africa, micronutrients deficiencies are prevalent among children under the age of 5 years 
and women in Kenya. According to Kenya National Nutrition Action Plan of 2012-2017, the most common micronutrient deficiencies include vitamin A deficiency (VAD), iron deficiency anaemia (IDA), iodine deficiency disorders (IDD) and zinc. VAD among under-fives (84.4\%); IDA among 6-72-month old (69\%) and among pregnant women (55.1\%); IDD (36.8\%); and zinc deficiency among mothers (52\%) and among children under 5 years $(51 \%)$. Iron deficiency is emerging as the most common condition among non-target groups with the prevalence of the deficiency among adolescents (Stevens \& Winter, 2008).

Maize (zea mays) is a vital staple and a main source of dietary protein in many areas of the developing world (De Groote et al., 2014) while sorghum (sorghum bicolor) is also a leading staple for many communities (Mui, 2014). Therefore, since maize and sorghum are staple foods in Kenya, as in much of sub-Saharan Africa, the successful introduction of maize-sorghum blend flours with plant based fortification could have a significant impact on reducing the prevalence of micronutrient and protein energy deficiencies in these areas (De Groote et al., 2014.; Fiedler et al., 2017) as well as reducing postharvest losses of fruits and vegetables as observed at both farm and market levels.

Some countries in Africa do not have mandatory maize flour fortification legislation (Enzama et al., 2017; Andrew \& Tulchinsky, 2015). Through the voluntary food fortification programs, governments and development partners have put a lot of efforts to start and scaleup cereal flour fortification in this region to enable consumers to benefit from staple flours with added nutritional benefits. Most cereal flours are traditionally milled in small scale hammer mills and do not go through fortification of any kind, and sometimes consumers choose to dehul the cereals before milling, therefore loosing on the nutritional benefits of wholemeal flours. There is seemingly inadequate information on the consumer side, and on the small scale millers side, there lacks quality control and quality assurance systems (Enzama et al., 2017) which may result to flour without adequate nutrients.

Horton, Alderman, Rivera, Horton, Alderman \& Rivera (2008), stated that micronutrient supplementation has been argued as the most promising and the most cost effective means of curbing the effects of diet induced micronutrient deficiencies. However, there is still uncertainty about how to effectively carry out nutrient supplementation and how to best reach the vulnerable populations. Therefore, this calls for a possibility of food to food fortification of widely consumed traditional staples like maize and sorghum to improve the nutritional content and hence reduce postharvest losses rather than devising schemes to distribute supplements (De Groote et al., 2020). In particular, plant based fortificants from the food system can be added to improve the nutritional content of traditional staple crops. Once a nutrient is introduced into a staple crop, an entire population can be easily reached and involved, and unlike supplementation, there is no need for repetitive interventions (Horton, 2006).

Consumer acceptance is key to the adoption of food product innovations (Chen et al., 2013). However, despite an apparent increase in consumer interest in food related technology, food product innovations success hinges on consumer behavioural response in the marketplace (Chen et al., 2013; Sajdakowska et al., 2018). Consumers are also primarily conditioned by their concern for health and there is a growing interest in healthy foods with various improvements in the negative attributes such as food lower in sodium, as well as the addition of beneficial ingredients such as pro-and prebiotics (Sajdakowska et al., 2018; Siegrist, 2008). Additionally, consumer demographic characteristics such as gender, education, age and personal motivation to engage in pro-health activities, play an important role in the acceptance of functional food (Kraus, 2015). As a consequence, consumers' attitudes toward new food products should be taken into account at an early stage of product development (Siegrist, 2008). Most research has focused on the producer characteristics, largely ignoring the perceived needs of the consumer. Plant based fortification can substantially alter the sensory characteristics of products, in particular, the colour and aroma of orange-fleshed sweet potato or vitamin A biofortified maize (De Groote et al., 2014). Central location testing (CLT) method has been applied to African consumers to evaluate consumer acceptance. However, one potential drawback of using CLT is that consumers have only a brief period of time to evaluate a product (typically $30 \mathrm{~min}$ ). Additionally consumers may be willing to pay a premium to try out a new product for the first time, so that the estimated willingness to pay may not reflect the product's intrinsic value (Meenakshi et al., 2012). Therefore, "home-use testing" (HUT) may be conducted, where the new product is tried in home situations for a few days, giving consumers enough time of interaction with the product so as to characterize it. The degree of researchers' control over the experiment is lower in HUT, so that it is possible that any observed variation across respondents is not necessarily because of intrinsic differences on how the product is perceived but on how the product was processed and consumed within the home (Boutrolle et al., 2007). But since HUT more closely mimics actual product use, it may be considered the gold standard (De Groote et al., 2014; Meenakshi et al., 2012). The main objective of this study was to assess consumer acceptance and likelihood to purchase (a more socially oriented approach) plant based fortified instant whole meal 
sorghum-maize flours, other than willingness to purchase (De Groote et al., 2020), which was more of an economic approach, in urban Eldoret, Kenya. In this case, the samples were fortified using natural fortificants: baobab powder (for iron and zinc), and orange fleshed sweet potatoes (for Vit A) and grain amaranth (for protein and other micronutrients). This paper attempts to account for product experience using HUT, where consumers tried the product for a few days at home using affective tests. The affective test seeks to assess the personal response (preference or acceptance) to a new product by a sample of representative consumers (De Groote et al., 2020).

Two different products: ugali, a stiff porridge and uji, $a$ thin porridge, products that are the most commonly prepared as staples by most consumers in Kenya were evaluated. (Boutrolle et al., 2005) demonstrated that products differ not only by their intrinsic characteristics (taste, nutrition, health), but also extrinsic factors (visual and social attributes). We thus expected that these differences would affect the outcome of the hedonic tests depending on the testing conditions (Boutrolle et al., $2005 \& 2007$ ).

\section{Sampling Design}

The study targeted urban consumers in 4-purposively sampled gated communities (estates) within Uasin Gishu County-Ainabkoi sub-county, specifically in Eldoret town, Kenya. This zone falls in the target area for promotion of instant flour varieties, given their prominent levels of maize/sorghum production as well as fruits and vegetable consumption. A list of the households in each of the estates, with middle and high income was obtained from the local area administration and thereafter households with at least one child aged 6-59 months were identified and stratified as a sampling frame of eligible households. Households that did not have that age of children were also included as another strata. Each strata was then randomly selected with sample sizes in each estate proportional to the total number of eligible households. In total, 154 households were selected, with 93 households representing mother-child pairs and 61 without children of that age. Each participating household signed an informed consent and all the respondents were literate.

\subsection{Study Design and Implementation}

Consumers derive satisfaction from attributes of the goods, therefore, when studying the market for new products, analysis of consumer's appreciation of its different attributes with consumer acceptance or affective tests is a necessity (De Groote, 2014; Kevin, L, 1966). This study adopted a cross-over study design based on a home-use test method where the product can be tested more times in a familiar environment despite its high cost and little control by the researcher.

There is a general assumption that a realistic HUT reveals more relevant hedonic data than CLT. HUT was used to test these products because maize and sorghum are mostly consumed at home and there was need for consumers to have been familiar with the products. Since the products were instant which was contrary to the normal way of preparing ugali and uji, HUT method gave the respondents adequate time to have repeated preparation of the product before evaluating it. Therefore, the evaluation was based on stabilized use rather than first impression. Ugali and uji were chosen because they are the most common short time cereal preparations in Kenya. Ugali a stiff porridge is normally prepared by mixing flour in boiling water for fourty minutes while uji requires more water and a little flour and takes about twenty minutes. However, since these products were instant, they were prepared by blending the instant flour with boiled water and consuming it without any further heating, which is not the norm in this context. It is also worth noting that the whole meal flours used to prepare both $u j i$ and ugali were extruded at $130^{\circ} \mathrm{C}$ using a single screw mini extruder developed by Purdue University with a processing capacity of approximately $45.4 \mathrm{~kg}$ of flour (100 pounds) per hour, at an energy cost of approximately $3.375 \mathrm{kWh}$ in the laboratory of the Food Processing Training \& Incubation Centre, University of Eldoret-Kenya.

A total of five (5) variations of whole meal instant flours, fortified with plant based materials (baobab, orange fleshed sweet potato and grain amaranth) were used for evaluation and were labelled with different codes (Table 1). The composition of the five instant composite flours was varied in as far as the sorghum and maize used, whereas the plant based fortificants were constant so as to give the flour a minimum of $25 \%$ RDA for the target micronutrients (Vit A, Fe and $\mathrm{Zn}$ ). The flour variations were evaluated one at a time, each for one week over 5-consecutive weeks. During each week the selected households received $1 \mathrm{~kg}$ of flour until all the variations were exhausted. During the first week of HUT, the selected households were visited by trained enumerators with a nutrition background who administered a questionnaire on demographic characteristics of the respondents. They also demonstrated how to prepare uji and ugali from these flour samples. Thereafter, the person responsible for cooking in the household, usually the wife of the household head, was asked to prepare uji as a mid-morning or afternoon snack, and ugali at dinner time, from the batch of flour in his/her own kitchen or dining table as the family watched. 
Each respondent head of household or mother scored the home made uji and ugali for appearance, aroma, texture in the hand, texture in the mouth, taste and overall acceptance, each on a 5-level hedonic scale, from $1=$ dislike very much to $5=$ like very much. Mothers further scored their child's overall acceptance of each prepared $u j i$ and ugali using the same 5-point hedonic scale. The 5-point scale was chosen because this scale is easy to use orally in any language and for any criterion. After each week of home use, the enumerators distributed the next variation of instant flour until all the 5 variations were covered and rated accordingly. At the end of the HUT study, respondents were asked to indicate how likely they were to purchase and use instant wholemeal flour products for use in making ugali and uji and what kind of packaging information would be important for them to better understand and appreciate the product.

Table 1. Composition of the five composite flour variations

\begin{tabular}{llllll}
\hline Ingredients $/ 100 \mathrm{~g}$ & \multicolumn{5}{l}{ Sample flours } \\
\hline & WB57 & RS46 & VJ34 & LU29 & NH14 \\
\hline Maize & - & 50 & 15 & 35 & 25 \\
Sorghum & 50 & - & 35 & 15 & 25 \\
Grain Amaranth & 20 & 20 & 20 & 20 & 20 \\
Baobab & 15 & 15 & 15 & 15 & 15 \\
Orange fleshed sweet potato (OFSP) & 15 & 15 & 15 & 15 & 15 \\
\hline
\end{tabular}

\subsection{Statistical Analysis}

In consumer acceptance or affective tests, consumers are typically asked to evaluate new products on a Likert scale, in which the responses are ordered but not necessarily equally spaced (De Groote et al., 2014). In this study a 5-point scale was used for HUT where the scores represent an ordered, rather than an interval variable. Results for sensory attributes were expressed as the mean \pm standard deviations (SD). Differences between the samples were statistically analyzed using one-way analysis of variance (ANOVA), followed by post hoc Tukey test, taking on $\mathrm{p}<0.05$. Statistical analysis was performed using SPSS version 22 (SPSS Inc., Chicago, IL, USA).

\section{Results and Discussion}

A total of 154 households participated in the study with $80 \%$ females and $20 \%$ males. The number of households with children below 5 years of age were $93(60 \%)$ and all the households that had children of 6 months-59 months fell in the category of 25-45 years. The highest level of education that the respondents had attained was tertiary, represented by $80 \%$, with the rest $(20 \%)$ having obtained middle level education. Majority of the respondents (70\%) earned a monthly income of above Ksh. 36000 (\$360), (see Table 2).

Table 2. Socio-demographic characteristics of respondents

\begin{tabular}{lll}
\hline Characteristics & Categories & Percentage (\%) \\
\hline Sex & Female & 80 \\
Age (Years) & Male & 20 \\
& $25-35$ & 24.5 \\
& $36-45$ & 35.5 \\
No of mothers with children aged 6-59 months & $46-55$ & 30 \\
Education level & 56 -and above & 10 \\
& 93 households & 60 \\
& Primary & - \\
Monthly average income (Ksh) & Middle level & 35 \\
& Tertiary & 65 \\
& $15000-25000$ & 05 \\
& $26000-35000$ & 25 \\
& $36000-45000$ & 55 \\
& 46000 -and above & 15 \\
\hline
\end{tabular}

$\mathrm{N}=154$

\subsection{Home-use Test Evaluation by Consumers}

In this section, we aligned our results and discussion to the respondents (consumers) in general. Based on a total 
population of 154 respondents who were issued with five samples of instant flour, the likeability scores were derived on a scale of $1-5$ where 1 was rated as dislike very much whereas 5 was rated as like very much (Table 3). Respondents rating for both $u j i$ and ugali made from the flour varieties was above the average of $\mathrm{M}=3.0$ which was an indication of preference for the flour varieties. Mean rating for ugali based on appearance revealed differences in the ratings thus an indication that consumers were able to make a distinction between the products during evaluation however, there was no significant differences between the flour varieties $(\mathrm{p}<0.05)$. A similar trend was observed for texture in hand, aroma, texture in mouth and overall acceptability. However, taste for ugali made from WB57 which had no maize was significantly different ( $<<0.05 ; \mathrm{M}=2.59)$ from scores for other flour varieties. Mean scores for ugali based on texture for all the flour varieties were insignificantly different even though the means for VJ34 (which had more sorghum than maize) were lower than the other variations. Based on the sensory attributes scores, general acceptance for ugali seems to correspond well with the sensory data.

Mean scores for $u j i$ made from the five instant flour varieties were above $M=3.5$ for all the sensory attributes and overall acceptability which was an indication of high likeability. However, appearance scores for uji made from RS46, and LU29 ( $<<0.05)$ were significantly different from WB57, VJ34 and NH14. This may be due to the higher amounts of sorghum comparatively and the fact that the darker colour is more associated to uji by consumers in Kenya than the lighter colour brought about by white maize. However, the overall acceptance of the flour variations for $u j i$ was statistically insignificant and with high mean scores $(M=4.15-M=3.83)$, indicating that the instant flours had high acceptance regardless of the variation in proportions of sorghum and maize.

Table 3. Consumer acceptance scores for ugali and uji made from 5 variations of -plant based fortified wholemeal instant flour samples among urban consumers

\begin{tabular}{llllllll}
\hline Products & $\begin{array}{l}\text { Sample } \\
\text { flours }\end{array}$ & \multicolumn{2}{l}{ Sensory Attributes } & & & $\begin{array}{l}\text { General } \\
\text { acceptability }\end{array}$ \\
\hline & & Appearance & Texture in hand & Aroma & Texture in mouth & Taste & \\
\hline Stiff porridge & WB57 & $3.68 \pm 0.90^{\mathrm{a}}$ & $3.44 \pm 1.06^{\mathrm{a}}$ & $3.29 \pm 1.2^{\mathrm{a}}$ & $3.23 \pm 1.10^{\mathrm{a}}$ & $2.59 \pm 1.24^{\mathrm{b}}$ & $3.18 \pm 1.19^{\mathrm{a}}$ \\
(Ugali) & RS46 & $3.43 \pm 1.17^{\mathrm{a}}$ & $3.64 \pm 0.97^{\mathrm{a}}$ & $3.33 \pm 1.17^{\mathrm{a}}$ & $3.44 \pm 1.18^{\mathrm{a}}$ & $3.38 \pm 1.19^{\mathrm{a}}$ & $3.50 \pm 1.09^{\mathrm{a}}$ \\
& VJ34 & $3.17 \pm 1.01^{\mathrm{a}}$ & $3.39 \pm 1.07^{\mathrm{a}}$ & $3.30 \pm 1.06^{\mathrm{a}}$ & $3.17 \pm 1.15^{\mathrm{a}}$ & $3.22 \pm 1.24^{\mathrm{a}}$ & $3.23 \pm 1.09^{\mathrm{a}}$ \\
& LU29 & $3.55 \pm 0.85^{\mathrm{a}}$ & $3.68 \pm 1.02^{\mathrm{a}}$ & $3.39 \pm 1.02^{\mathrm{a}}$ & $3.47 \pm 1.24^{\mathrm{a}}$ & $3.26 \pm 1.14^{\mathrm{a}}$ & $3.48 \pm 1.08^{\mathrm{a}}$ \\
& NH14 & $3.36 \pm 0.97^{\mathrm{a}}$ & $3.45 \pm 1.00^{\mathrm{a}}$ & $3.60 \pm 0.98^{\mathrm{a}}$ & $3.37 \pm 1.09^{\mathrm{a}}$ & $3.21 \pm 1.18^{\mathrm{a}}$ & $3.17 \pm 1.15^{\mathrm{a}}$ \\
Thin porridge & WB57 & $4.22 \pm 0.76^{\mathrm{a}, \mathrm{b}}$ & $4.04 \pm 0.76^{\mathrm{a}}$ & $4.04 \pm 0.76^{\mathrm{a}}$ & $3.93 \pm 0.88^{\mathrm{a}}$ & $4.07 \pm 0.95^{\mathrm{a}}$ & $4.15 \pm 0.75^{\mathrm{a}}$ \\
& RS46 & $3.79 \pm 1.03^{\mathrm{a}}$ & $3.89 \pm 0.87^{\mathrm{a}}$ & $3.70 \pm 1.08^{\mathrm{a}}$ & $3.96 \pm 0.94^{\mathrm{a}}$ & $3.75 \pm 1.03^{\mathrm{a}}$ & $3.83 \pm 0.99^{\mathrm{a}}$ \\
& VJ34 & $4.03 \pm 0.75^{\mathrm{a}, \mathrm{b}}$ & $3.92 \pm 0.77^{\mathrm{a}}$ & $3.97 \pm 0.73^{\mathrm{a}}$ & $3.92 \pm 0.68^{\mathrm{a}}$ & $3.79 \pm 0.87^{\mathrm{a}}$ & $3.90 \pm 0.75^{\mathrm{a}}$ \\
& LU29 & $3.88 \pm 0.91^{\mathrm{a}}$ & $4.03 \pm 0.80^{\mathrm{a}}$ & $3.89 \pm 0.85^{\mathrm{a}}$ & $4.11 \pm 0.77^{\mathrm{a}}$ & $3.87 \pm 1.03^{\mathrm{a}}$ & $4.07 \pm 0.75^{\mathrm{a}}$ \\
& NH14 & $3.96 \pm 0.86^{\mathrm{a}, \mathrm{b}}$ & $4.09 \pm 0.72^{\mathrm{a}}$ & $4.03 \pm 0.88^{\mathrm{a}}$ & $3.88 \pm 0.95^{\mathrm{a}}$ & $4.03 \pm 0.86^{\mathrm{a}}$ & $4.01 \pm 0.92^{\mathrm{a}}$ \\
\hline
\end{tabular}

Mean ratings of product in that category based on a 5-point hedonic scale ranging from 1-extremely dislike to 5 like very much; $\mathrm{N}=$ 154.Values represent the means (M); Values followed by different superscripts letters in the same column are significantly different from each other $(\mathrm{p}<0.05)$.

High overall acceptance scores for uji to ugali across the flour varieties was attributed to higher consumption of uji by both urban and rural consumers especially at breakfast and late afternoon snack in Kenya. These findings are consistent with consumption patterns of adults in urban Ethiopia (Gunaratna et al., 2016), and since the scores for uji and ugali were different, in future asking the respondents to state the reasons behind their rating would provide valuable additional information for their preferences.

A similar pattern of overall acceptability was observed for children's and mother's overall scores for both sets of products. The differences between the ratings were found to be insignificant (Table 4). This pattern of rating for both mother and children was attributed to mothers rating the products on behalf of their children as percieved. In addition, mean scores for uji $(\mathrm{M}=3.98-\mathrm{M}=3.78)$ by children were higher than mean scores for ugali $(\mathrm{M}=3.45$ - $\mathrm{M=2.92)}$ across the five varieties whereas mothers had higher ratings for both uji $(\mathrm{M}=4.15-\mathrm{M}=3.83)$ and lower ratings for ugali $(\mathrm{M}=3.50-\mathrm{M}=3.17)$. Mothers overall scores for ugali made from the different flour varieties were driven by aroma and taste, while overall acceptance scores for $u j i$ were driven by all the sensory attributes. Since the children in this research were within the age category of 6-59 months, majority of them were still being introduced to different foods which is mostly in the liquid or semi liquid, they are bound to have higher acceptability rates for the unknown more than the mothers who may not appreciate the semi-solid product as prepared for the children for ease of digestion. 
Table 4. Mean overall acceptability score for uji and ugali made from the naturally fortified wholemeal instant flours for mothers and children

\begin{tabular}{lllll}
\hline Flour samples & \multicolumn{2}{l}{ Thin porridge (uji) } & \multicolumn{2}{l}{ Stiff porridge (ugali) } \\
\hline & Children's rating & Mother's rating & Children's rating & Mother's rating \\
\hline WB57 & $3.97 \pm 0.69^{\mathrm{a}}$ & $4.15 \pm 0.75^{\mathrm{a}}$ & $2.92 \pm 1.19^{\mathrm{a}}$ & $3.18 \pm 1.19^{\mathrm{a}}$ \\
RS46 & $3.78 \pm 0.89^{\mathrm{a}}$ & $3.83 \pm 0.98^{\mathrm{a}}$ & $3.41 \pm 1.08^{\mathrm{a}}$ & $3.50 \pm 1.09^{\mathrm{a}}$ \\
VJ34 & $3.85 \pm 0.73^{\mathrm{a}}$ & $3.90 \pm 0.75^{\mathrm{a}}$ & $3.26 \pm 1.18^{\mathrm{a}}$ & $3.23 \pm 1.09^{\mathrm{a}}$ \\
LU39 & $3.96 \pm 0.72^{\mathrm{a}}$ & $4.07 \pm 0.75^{\mathrm{a}}$ & $3.45 \pm 1.02^{\mathrm{a}}$ & $3.48 \pm 1.08^{\mathrm{a}}$ \\
NH14 & $3.98 \pm 0.81^{\mathrm{a}}$ & $4.01 \pm 0.92^{\mathrm{a}}$ & $3.15 \pm 1.24^{\mathrm{a}}$ & $3.17 \pm 1.15^{\mathrm{a}}$ \\
\hline
\end{tabular}

Mean ratings of product in that category based on a 5-point hedonic scale ranging from 1-extremely dislike to 5 like very much; for both mother and children; $\mathrm{N}=93$; Values represent the means; Values followed by different superscripts letters in the same column are significantly different from each other $(\mathrm{p}<0.05)$.

\subsection{Consumer Acceptability by Gender}

Analysis of consumer acceptability of uji and ugali made from the naturally fortified wholemeal instant flours showed that acceptability differed by gender (Fig.1). Likings for males were higher for both uji $(\mathrm{M}=3.94$ and $\mathrm{M}=4.29)$ and ugali $(\mathrm{M}=3.38$ to $\mathrm{M}=3.80)$ across the five samples. Also noted that for both gender, respondents tended to prefer uji to ugali across all the varieties of flours used. Both Male and female respondents most preferred uji made from VJ34 (with a ratio of more sorghum than maize) flour composite while rating uji made from NH14 (with more maize than sorghum) flour variation lowest. Additionally, they least preferred ugali made from WB57 (all sorghum) flour variation. Female respondents scores for ugali varied between M=2.96 and $\mathrm{M}=3.44$, with an indication that they mostly preferred ugali made from LU29 (more maize than sorghum) whereas mean scores for uji varied between 3.75 to 4.13 . Generally, the acceptability scores for gender were not statistically different. However, males are known to have an inquisitive nature of exploring new food products and tastes and are likely to quickly adopt to new tastes as individuals more than females who may be uncertain about the reception of product by all their family members. This is in concert with the findings of Vijaya, Aparanjini \& Lahari (2017), that women want more interaction whereas men want quick answers, and they look into satisfying an immediate need. In a HUT study, appreciation of a product may grow with repeated use and women are able to introduce a product that other family members have appreciated.

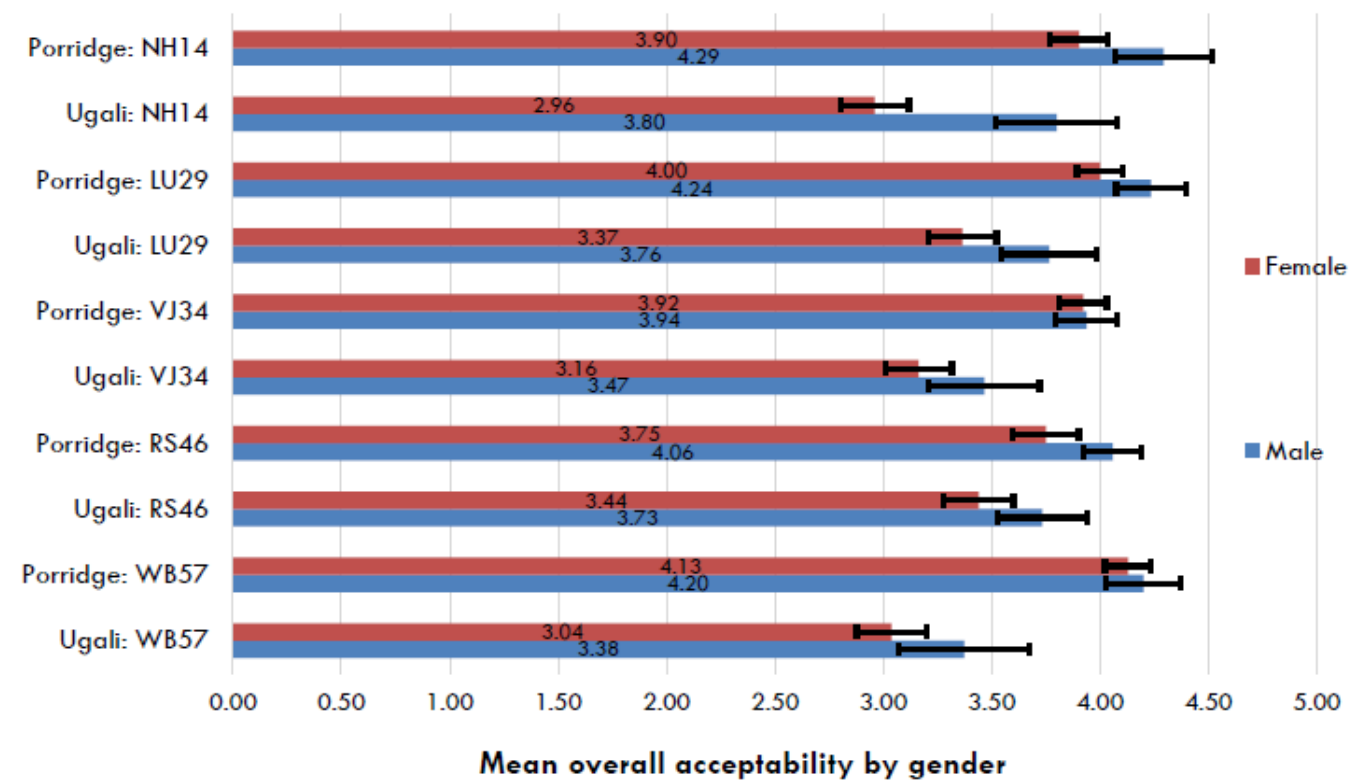

Figure 1. Mean consumer acceptability for uji and ugali made from the naturally fortified instant flours by gender (error bars $=$ standard deviation). Values shown in the middle of the error bars are mean scores

\subsection{Assessing Consumers'Likelihood to Purchase Wholemeal Instant Flour}

During the weekly evaluations, consumers received information on the nutritional quality of the flours and 
thereafter they were asked to evaluate their likelihood to purchase the flour on a 7-point scale ranging from 1-extremely unlikely to purchase to 7 - extremely highly likely to purchase (Table 5). It was noted that $2 \%, 3 \%$ and 5\% of respondents indicated that they were extremely unlikely, not likely and slightly likely to purchase the instant whole meal flour respectively, whereas those likely, extremely likely and extremely highly likely to purchase the products were 10\%, 20\% and 55\% respectively. Therefore those likely to purchase the product add up to $85 \%$ which is a good sign for a new product.

Table 5. Distribution of respondents overall evaluation on likelihood and reasons to purchase wholemeal instant products with plant based fortification

\begin{tabular}{llllll}
\hline Likelihood of purchase & $\mathrm{n}$ & $\%$ & Reasons for purchase & $\mathrm{n}$ & $\%$ \\
\hline 1.Extremely unlikely to purchase & 3 & 02 & For normal family use & 108 & 70 \\
2.Not likely to purchase & 5 & 03 & For good nutrition & 111 & 72 \\
3.Slightly likely to purchase & 8 & 05 & For health reasons & 105 & 68 \\
4.Moderately likely to purchase & 8 & 05 & For variation of family options & 113 & 74 \\
5.Likely to purchase & 15 & 10 & For childrens' weaning & 97 & 63 \\
6.Highly likely to purchase & 30 & 20 & For childrens' snack and well being & 120 & 78 \\
7. Extremely and highly likely to purchase & 85 & 55 & To save time for self & 119 & 77 \\
N=154 & & & For convenience for self & 109 & 71 \\
& & For ease of use for all family & 100 & 65 \\
& & members to do it themselves & & \\
& & & &
\end{tabular}

Likelihood to purchase often involves consumer market analysis which traditionally deals with demand for homogenous goods as determined by a set of relevant prices and demographic variables. Demand for quality traits, however, need not be determined by the same set of variables. This is because a consumer's utility increases with a particular quality whereas another consumer utility decreases (Kimenju \& De Groote, 2008). Consumer acceptance of food cannot be reduced to perceived benefits only (Siegrist, 2008; Muñoz \& Civille, 1987), therefore, further examination of factors influencing adoption on a 5-point scale ranging from 1-definately not to 5-definitely yes revealed that consumer acceptance and adoption of the flour varieties was associated with benefits such as favourable taste, nutrition and health benefits, convenience, price, advertisement and introduction by a friend. (see Table 5). These findings regarding how the provision of nutrition information translates into improved acceptances are consistent with findings from other studies of consumer acceptance of nutritious orange maize in rural Zambia (Meenakshi et al., 2012). Suitability of the products for family use was rated highest $(M=4.59)$ followed by instructions for use and ease of preparation at $M=4.48$ and $M=4.47$ respectively. It was noted that influence of media adverts $(\mathrm{M}=3.10)$ was the only attribute that was rated at $\mathrm{M}<4$. Muñoz \& Civille (1987), observed similar results based on advertisement, that food products are often associated with nature, because nature and naturalness are positively valued concepts (Rozin, 2006). However, media coverage may have an influence in consumer adoption of the products especially when the products are rolled out on the market. In line with this study, results suggests that a dichotomy between extrinsic and intrinsic aspects of a product influence acceptance and adoption.

Table 5. Factors influencing adoption of the flour varieties

\begin{tabular}{lll}
\hline & Product attributes & Mean \\
\hline 1. & Clarity of label & $4.32 \pm 043$ \\
2. & Price & $4.14 \pm 0.40$ \\
3. & Instructions for preparation and use & $4.48 \pm 0.48$ \\
4. & Ease of preparation & $4.42 \pm 0.52$ \\
5. & Favourable taste & $4.27 \pm 0.43$ \\
6. & Favourable quality packaging & $4.00 \pm 0.67$ \\
7. & Introduced by reliable friend & $4.20 \pm 0.52$ \\
8. & Fit for whole family & $4.59 \pm 0.33$ \\
9. & Adequate information on health benefits & $4.38 \pm 0.42$ \\
10. & Adequate information on nutrition benefits & $4.30 \pm 0.42$ \\
11. & Well advertised & $3.10 \pm 0.33$ \\
12. & Fit for family nutrition needs & $4.20 \pm 0.34$ \\
13. & Fit for family health needs & $4.13 \pm 0.36$ \\
\hline
\end{tabular}


Journal of Food Research; Vol. 9, No. 3; 2020

ISSN 1927-0887 E-ISSN 1927-0895

Published by Canadian Center of Science and Education

\begin{tabular}{|c|c|c|c|c|c|c|c|c|c|c|c|c|c|c|c|c|c|c|}
\hline & & 1. & 2. & 3. & 4. & 5. & 6. & 7. & 8. & 9. & 10. & 11. & 12. & 13. & 14. & 15. & 16. & 17. \\
\hline 1. & Gender & - & & & & & & & & & & & & & & & & \\
\hline 2. & Age & .0404 & & & & & & & & & & & & & & & & \\
\hline 3. & Income & .0047 & .0005 & & & & & & & & & & & & & & & \\
\hline 4. & Education & -.0627 & .1053 & $.1986^{* * *}$ & & & & & & & & & & & & & & \\
\hline 5. & Clarity of label & $.1733^{*}$ & -.0164 & .0135 & $.1582 *$ & & & & & & & & & & & & & \\
\hline 6. & Price & .1056 & .0361 & .0535 & .0681 & .1069 & & & & & & & & & & & & \\
\hline 7. & $\begin{array}{l}\text { Instructions for } \\
\text { preparation and use }\end{array}$ & $-.2963 * *$ & -.0399 & -.0210 & .0423 & .0146 & $.1597 *$ & & & & & & & & & & & \\
\hline 8. & Easy to prepare & -.0580 & -.0858 & -.0325 & $.2063 * *$ & .0671 & .0046 & $.1540 *$ & & & & & & & & & & \\
\hline 9. & Favourable taste & .0986 & .0594 & .0884 & .0226 & .0833 & $.3948 * *$ & $.4621 * *$ & $.1486^{*}$ & & & & & & & & & \\
\hline 10. & $\begin{array}{l}\text { Favourable quality } \\
\text { packaging }\end{array}$ & -.0332 & -.0035 & .0786 & .0960 & .0422 & $.1982 * *$ & $.1987^{* *}$ & $.1798^{* *}$ & $.1868^{* *}$ & & & & & & & & \\
\hline 11. & $\begin{array}{l}\text { Introduced by } \\
\text { reliable friend }\end{array}$ & .0553 & -.1182 & .0151 & -.0134 & .0538 & .0390 & $.1486^{*}$ & .1107 & .0426 & $.1425^{*}$ & & & & & & & \\
\hline 12. & $\begin{array}{l}\text { Fit for whole } \\
\text { family }\end{array}$ & .0799 & -.0255 & -.0829 & $-.2276^{* *}$ & -.0394 & .0068 & $.1762 *$ & $.2333^{* *}$ & .1327 & .0031 & $.2446^{* *}$ & & & & & & \\
\hline 13. & $\begin{array}{l}\text { Fit for family } \\
\text { health needs }\end{array}$ & $-.2222^{*}$ & -.0483 & -.0581 & -.0618 & $.1789^{* *}$ & .0760 & $.1405^{*}$ & $.1450^{*}$ & .1234 & .1271 & $.1952^{* *}$ & $.1922^{* *}$ & & & & & \\
\hline 14. & $\begin{array}{l}\text { Fit for family } \\
\text { nutrition needs }\end{array}$ & .0654 & -.0096 & -.0978 & $-.2142 * *$ & -.0217 & .0278 & $.1703^{*}$ & $.2433^{* *}$ & -.1164 & .0005 & $.2094 * *$ & $.9965^{* *}$ & $.1824 *$ & & & & \\
\hline 15. & Well advertised & .0840 & -.1098 & -.1238 & $-.1380 *$ & -.0211 & .0420 & .0557 & $.1643 *$ & .0751 & $.2556^{* *}$ & $.4031^{* *}$ & $.2308 * *$ & .1171 & $.1987^{* *}$ & & & \\
\hline 16. & $\begin{array}{l}\text { Adequate } \\
\text { information on } \\
\text { health benefits }\end{array}$ & $.1682 *$ & -.0576 & -.1214 & -.1284 & $.1793^{*}$ & .1154 & $.3320 * *$ & $.2817^{* * *}$ & $.1960^{* *}$ & .1152 & $.2570^{* * *}$ & $.5966^{* *}$ & $.7044 * *$ & $.6886^{* *}$ & $.1720 *$ & & \\
\hline 17. & $\begin{array}{l}\text { Adequate } \\
\text { information } \\
\text { on nutrition } \\
\text { benefits }\end{array}$ & .0367 & -.0129 & .0110 & -.0627 & .0087 & $.4262 * *$ & $.2224 * *$ & .0875 & $.6323 * *$ & -.0151 & -.0368 & .0256 & -.0232 & -.0158 & .0043 & .0296 & - \\
\hline
\end{tabular}

$\mathrm{N}=154 ;$ Means derived from 5-point scale ranging from 1-definitely not to 5-definitely yes; ${ }^{*} \mathrm{p}<.05 ; \quad * * \mathrm{P}<.01$ 


\subsection{The Correlation Relationships between Likelihood of Adoption Variables}

Correlation analysis of likelihood of adoption indicates that gender had positive significant correlations with clarity of label $(r=.1733)$, adequacy of information on health benefits $(r=.1682)$ at $p<.05$ (see Table 6). However, gender and fit for family health needs $(r=-.2105)$ and instructions for use were found to have a negative correlation $(r=-.952, p<.01)$. Education was a general key attribute for likelihood of adoption with several attributes noting positive correlations for all the respondents. These include income $(r=.1986)$, ease of preparation $(\mathrm{r}=.2063)$ at $\mathrm{p}<.01$, and clarity of label $(\mathrm{r}=.1582)$ at $\mathrm{p}<.05$. Attributes with significant negative correlations with education included fit for whole family $(r=-.2276)$, fit for family nutrition needs $(r=-.2142)$ at $\mathrm{p}<.01$, and with a product that is well advertised $(\mathrm{r}=-.1380, \mathrm{p}<.05)$. Price of product and favorable taste $(\mathrm{r}$ $=.3948)$, adequate information on nutrition benefits $(\mathrm{r}=.4262)$, favourable quality packaging $(\mathrm{r}=.1982)$ were all positively and significantly correlated for purposes of likelihood of adoption, all at $\mathrm{p}<.01$, and also instructions for preparation and use $(\mathrm{r}=.1597)$ at $\mathrm{p}<.05$. A product that was well advertised and with favourable quality packaging $(\mathrm{r}=.2556)$, introduced by a reliable friend $(\mathrm{r}=.4031)$, fit for whole family $(\mathrm{r}=.2308)$ and fit for family nutrition needs $(\mathrm{r}=.1987)$ were all positively correlated with likelihood of purchase at $\mathrm{p}<.01$ whereas adequate information on nutrition benefits $(\mathrm{r}=.1720)$ was at $\mathrm{p}<.05)$. A product that had favourable taste also had a very high positive correlation $(\mathrm{r}=.6323)$ with adequacy of information on nutrition benefits and also adequate information on health benefits $(\mathrm{r}=.1960)$ at $\mathrm{p}<.01$ towards likelihood of purchase. Making the product known to a prospective consumer by a friend had a significant and positively high correlation with a product that had adequate information on health benefits $(\mathrm{r}=.2570)$ and fit for the whole family $(\mathrm{r}=.2446)$, among others, on likelihood of purchase, at $\mathrm{p}<.01$. A product that was fit for family health needs $(\mathrm{r}=.5966)$, with adequate media coverage $(\mathrm{r}=.6886)$, and fit for family nutrition needs $(\mathrm{r}=.7044)$ were all significantly positively correlated $(\mathrm{p}<.01)$ with adequacy of information on health benefits, thus having a positive influence on likelihood of purchase and adoption. Scientists, dietitians, and the public agree that an optimal diet should be a primary focus of a healthy lifestyle (Vijaya \& Lahari, 2017). Notably, both intrinsic and extrinsic product qualities affect consumer likelihood of purchase and the more convinced consumers are with new product qualities, the more likely they are to adopt it even though not all the attributes tested gave the same degree of likelihood to adopt.

\section{Conclusion}

From the experience of using HUT, we conclude that despite the costs and logistics involved, this method provides adequate time for proper evaluation in familiar environments (home set up). This method is also efficient in dissemination strategies by identifying the knowledge factors that can help influence consumer acceptance, adoption, and ultimately, improvement adoption of a new food product. Sensory evaluation results indicate that sensory characteristics of all the tested products are positive despite the slight variations. This does not pose a hindrance to acceptance and likelihood to adopt and could also enable the food processing industry to produce product line variations, especially since the production capacity would be determined by the availability of the ingredients used in formulations which may vary due to seasonality and sometimes low production by farmers. This is also good for better profit margins by small scale processors as they strive to satisfy different consumer health and nutrition needs. Producing a variety of product lines with varying tastes and visual appeals will also satisfy different categories of consumers by age, social orientation, and cultural background. In this project, we were more concerned about curbing postharvest losses and thus the use of plant based fortificants to enable consumers to realize the nutrition benefits therewith and thus maximize community efforts in reducing losses. The option of using inorganic fortificants is also open to industry and would be more sustainable. However, as consumers increasingly become more health conscious, they are moving towards an increased use of natural ingredients. Consumers are also interested in clear and adequate information about a new product. Since this product was instant and the preparation method was moving the consumers away from the norm, we would expect not very high acceptability ratings. A consumer requires to get used to a new norm which may take while. This study also targeted urban consumers who are of middle and higher level income, and it would be interesting if the rural community is also studied with an alternative food to food fortified product which is affordable to the lower income groups that are more vulnerable to malnutrition.

\section{Acknowledgements}

This work was funded in whole by the United States Agency for International Development (USAID) Bureau for Food Security under Agreement \# AID-OAA-L-12-00003 as part of Feed the Future Innovation Lab for Food Processing and Post-harvest Handling. Any opinions, findings, conclusions, or recommendations expressed here are those of the authors alone. 


\section{Conflict of interest}

The author declares no potential conflicts of interest with respect to the research, authorship, and/or publication of this article.

\section{Research involving human participants}

Written informed consent were obtained from each participating households.

\section{References}

Andrew, M., \& Tulchinsky, T. (2015). Commentary: Food Fortification: African Countries Can Make More Progress. Advances in Food Technology and Nutritional Sciences, SE(1), S22-80. https://doi.org/10.17140/AFTNSOJ-SE-1-104

Bailey, R. L., Denby, H. N. B., Sherif, K., Steinbaum, S., \& Schacky, C. V. (2015). Perceptions of a healthy diet insights from a 3-countrysurvey. Nutrition Today, 50(6), 282-287. https://doi.org/10.1097/NT.0000000000000119

Black, R. E., Allen, L. H., Bhutta, Z. A., Caulfield, L. E., de Onis, M., \& Ezzati, M. (2008). Maternal and child undernutrition: global and regional exposures and health consequences. The Lancet, 371(9608), 243-260. https://doi.org/10.1016/S0140-6736(07)61690-0

Boutrolle, I., Delarue, J., Arranz, D., Rogeaux, M., \& Köster, E. P. (2007). Central location test vs. home use test: Contrasting results depending on product type. Food Quality and Preference, 18(3), 490-499. https://doi.org/10.1016/j.foodqual.2006.06.003

Boutrolle, I., Arranz, D., Rogeaux, M., \& Delarue, J. (2005). Comparing central location test and home use test results: Application of a new criterion. Food Quality and Preference, 16(8), 704-713. https://doi.org/10.1016/j.foodqual.2005.03.015

Chen, Q., Anders, S., \& An, H. (2013). Measuring consumer resistance to a new food technology: A choice experiment in meat packaging. Food Quality and Preference, 28(2), 419-428. https://dx.doi.org/10.1016/j.foodqual.2012.10.008

De Groote, H., Chege, C. K., Tomlins, K., \& Gunaratna, N. S. (2014). Combining experimental auctions with a modified home-use test to assess rural consumers' acceptance of quality protein maize, a biofortified crop. Food Quality and Preference, 38, 1-13. https://dx.doi.org/10.1016/j.foodqual.2014.04.014

De Groote, V. M., Mario, F., Augustino, O., Emmanuel, A., Kwaku, G. D., Michael, N., \& Bruce, R. H. (2020). Consumer acceptance and willingness to pay for instant cereal products with food-to-food fortification in Eldoret, Kenya. https://dx.doi.org/10.1177/0379572119876848

Enzama, W., Afidra, R., Johnson, Q., \& Verster, A. (2017). Africa maize fortification strategy 2017-2026. Smarter futures.

Fiedler, J. L., Afidra, R., Mugambi, G., Tehinse, J., Kabaghe, G., \& Zulu, R., (2014). Maize flour fortification in Africa: markets, feasibility, coverage, and costs. Annals of the New York Academy of Sciences, 1312, 26-239. https://doi.org/10.1111/nyas.12266

Gunaratna, N. S., Bosha, T., Belayneh, D., Fekadu, T., \& De Groote, H. (2016). Women's and children's acceptance of biofortified quality protein maize for complementary feeding in rural Ethiopia. Journal of the science of food and agriculture, 96(10), 3439-3445. https://doi.org/10.1002/jsfa.7526

Horton, S., Alderman, H., Rivera, J. A., Horton, S., Alderman, H., \& Rivera, J. A. (2008). Cp malnutrition and hunger. Horton. p. 1-40.

Horton, S. (2006). Symposium: Food Fortification in Developing Countries. Journal of Nutrion, 136(March), 1059-1063.

Jonker, F. A. M., te Poel, E., Bates, I., \& Boele, van H. M. (2017). Anaemia, iron deficiency and susceptibility to infection in children in sub-Saharan Africa, guideline dilemmas. British Journal of Haematology, 177(6), 878-883. https://doi.org/10.1111/bjh.14593

Kelvin, L. A. (1966). New Approach to Consumer Theory. The Journal of Political Economy, 74(2), 132-157. https://doi.org/10.1086/259131

Kimenju, S. C., \& De Groote, H. (2008). Consumer willingness to pay for genetically modified food in Kenya. Agricultural Economics, 38(1), 35-46. https://doi.org/10.1111/j.1574-0862.2007.00279.x 
Kraus, A. (2015). Factors influencing the decisions to buy and consume functional food. British Food Journal, 117(6), 1622-1636. https://doi.org/10.1108/BFJ-08-2014-0301

Meenakshi, J. V., Banerji, A., Manyong, V., Tomlins, K., Mittal, N., \& Hamukwala, P. (2012). Using a discrete choice experiment to elicit the demand for a nutritious food: Willingness-to-pay for orange maize in rural Zambia. Journal of Health Economics, 31(1), 62-71. https://dx.doi.org/10.1016/j.jhealeco. 2012.01.002

Muui, C. (2014). Identification and characterization of sorghum (Sorghum bicolor (L) Moench) landraces and improvement of on-farm seed production in Eastern Kenya. Unpublished doctoral thesis. Kenyatta University, Kenya. 1-243.

Müller, O., \& Michael, K. (2005). Malnutrition and health in developing countries. Canadian Medical Association, 173(3), 279-286. https://doi.org/10.1503/cmaj.050342

Muñoz, A. M., \& Civille, G. V. (1987). Factors affecting perception and acceptance of food texture by American consumers. Food Reviews International, 3(3), 285-322. https://dx.doi.org /10.1080/87559128709540817

Proietti, I., Frazzoli, C., \& Mantovani, A. (2015). Exploiting nutritional value of staple foods in the world's semi-arid areas: risks, benefits, challenges and opportunities of sorghum. Healthcare, 3(2), 172-193. https://doi.org/10.3390/healthcare3020172

Sajdakowska, M., Królak, M., Zychowicz, W., \& Marzena, J-Z. (2018). Acceptance of food technologies, perceived values and consumers' expectations towards bread. A survey among polish sample. Sustainability, 10(4), 1281. https://doi.org/10.3390/su10041281

Siegrist, M. (2008). Factors influencing public acceptance of innovative food technologies and products. Trends in Food Science and Technology, 19(11), 603-608. https://dx.doi.org/10.1016/j.tifs.2008.01.017

Stevens, R., \& Winter-Nelson, A. (2008). Consumer acceptance of provitamin A-biofortified maize in Maputo, Mozambique. Food Policy, 33(4), 341-351. https://doi.org/10.1016/j.foodpol.2007.12.003

Rozin, P. (2006). Naturalness judgments by lay Americans: process dominates content in judgments of food or water acceptability and naturalness. Judgment and Decision Making Journal, 1(2), 91-97.

Vijaya, L. V., Aparanjini, N. D., \& Lahari, G. (2017). Impact of gender on consumer purchasing behaviour. Iosr Journal of business and management, 19(8), 33-36.

\section{Copyrights}

Copyright for this article is retained by the author(s), with first publication rights granted to the journal.

This is an open-access article distributed under the terms and conditions of the Creative Commons Attribution license (http://creativecommons.org/licenses/by/4.0/). 